\title{
SARCASTIC 'LIKE': A CASE STUDY IN THE INTERFACE OF SYNTAX AND SEMANTICS
}

\author{
Elisabeth Camp \\ University of Pennsylvania \\ John Hawthorne \\ Oxford University
}

The expression 'Like' has a wide variety of uses among English and American speakers. It may describe preference, as in

(1) She likes mint chip ice cream.

It may be used as a vehicle of comparison, as in

(2) Trieste is like Minsk on steroids.

Sometimes it is used among American adolescents as quasi-quotational device that reenacts a private or public drama, as in

(3) She was like, we need to get out of here fast. ${ }^{1}$

And sometimes it used scattershot by said adolescents (and others) as a hedging discourse particle (cf. Sigel 2002), as in

(4) He got, like, eight job offers in his fourth year of grad school.

Each of these uses raises distinct theoretical issues: What exactly is the second relatum of the preferential 'like'? Does the 'like' of comparison express a constant, trivial relation or a contextually variable, restricted one? How do the possible objects of quotational 'like' differ from those for standard quotation? How does the hedging function performed by the discourse particle relate to the use of comparative 'like' as a hedge? And so on. 
Here we focus on yet another use of 'Like': as a vehicle of sarcasm. In this use, it patterns with 'As if', as in

(5) $\{$ Like/ As if $\}$ that's a good idea.

Although this use too can sound like a contemporary invention of Californian adolescents, it is neither very recent nor unique to American English. It is also found in (at least) German, as als ob ("as if"), in Russian, as mozhno podumat ("It is possible to think"), and in French, as si tu crois ("if you think") (Haiman 1998).

In $§ 1$ we establish that sentences containing sarcastic 'Like' cannot simply be assimilated to the general phenomenon of sarcasm: sarcastic 'Like' exhibits distinctive semantic and syntactic constraints that are not shared by bare sarcasm, and that call out for systematic explanation. In $\$ 2$ we focus on one distinctive syntactic feature of sarcastic 'Like'-its "front-preferring" nature-and use this feature to explain some of the observed behavior. Finally, in $\S 3$ we present two competing accounts of its semantic contribution, neither of which can be easily refuted, and both of which are more explanatory than the view that the operation of sarcastic 'Like' is entirely pragmatic. We survey some data for adjudicating between those theories, and conclude that 'Like' functions to mark an illocutionary force. The picture that emerges is surprising, not only because it falsifies the widely held, if rarely articulated, assumption that sarcasm is a wholly pragmatic phenomenon, but also because it falsifies the nearly-aswidely-held assumption that illocutionary force lies outside the proper domain of semantics.

\section{§1: Bare and 'Like'-prefixed Sarcasm}

In this section, we identify three significant differences between the general phenomenon of sarcasm and the sarcastic use of 'Like' or 'As if'. By 'sarcasm', we mean roughly what Quintillian meant two thousand years ago: speech in which "we understand something which is the opposite of what is actually said" $(95 / 1920,401)$. We aren't committed to any precise theoretical demarcation of the differences among sarcasm, 'jocularity' and verbal irony; some people deny there is any such difference, while others think that sarcasm is either more open and "frank," or more focused, negative, and critical than other sorts of verbal irony. We do believe, though, that all of the examples we discuss would be intuitively classified as sarcasm by ordinary speakers.

\subsection{Illocutionary Force and Markers Thereof}

The first of the three contrasts between bare sarcasm and sarcastic 'Like' or 'As if' to which we want to draw attention relates to illocutionary force. In 
general, utterances with any illocutionary force, including expressives, questions, orders, and optatives, can be used sarcastically:

(6) Thanks for holding the door. (uttered in the face of a door slamming shut)

(7) Could I tempt you to eat just one more slice of pie? (addressed to someone who has just eaten most of the pie) ${ }^{2}$

(8) Rage on, dude! (said in response to a dry academic lecture)

(9) Would that I were back in dear old England now. (uttered when something undesirable is saliently taking place in England)

(10) Poor you: stuck on the beach sipping daquiris, without even any grading to keep you occupied.

Examples like (6) through (10) are fully continuous with sarcastic utterances of declarative sentences, such as

(11) That's a good idea.

(12) I've never heard that excuse before.

(13) You should tell that to the judge.

(14) Everyone agrees that his writing is a pleasure to read.

There are no systematic differences in the way that bare sarcasm applies to utterances of sentences with declarative and other grammatical moods. In all of these cases, the speaker pretends to make a speech act, but doesn't intend to be taken as seriously undertaking that act. Instead, she either presents the speech act as the opposite of what it would be appropriate to sincerely utter in those circumstances (as in (8) through (10)), or else she evokes an alternative situation $S$ in which the actual utterance would be appropriate, where $S$ is in some salient sense the opposite of the situation at hand (as in (6) and (7)). ${ }^{3}$ Often, but not always, the speaker also thereby implicates a further message: for instance, in (7), the speaker in effect rebukes the addressee for being greedy; in (9), the speaker communicates that he is glad not to be in England; and in (11), the speaker implicates that the plan is not a good idea. ${ }^{4}$

Bare sarcasm is thus illocutionarily highly flexible. By contrast, sarcastic 'Like' and 'As if' are only felicitous when combined with declarative sentences. Thus, (11) through (14) can all be prefixed smoothly with 'As if' or 'Like'; but none of (6) through (10) can be. Utterances of (6) through (10) may not always be utterly infelicitous when prefixed with 'Like'; but we believe that in those cases 'Like' is not being used to express sarcasm, but rather is functioning in the quasi-quotational way, or else simply as an interjection, much like 'Um' or 'So'. This hypothesis is supported by the fact that utterances of (6) through (10) which are prefaced by 'Like' sound considerably better with a pause between 'Like' and the rest of the sentence, and by the fact that when those sentences are prefixed 
with 'As if', which lacks any use as an interjection or quasi-quotational marker, they are totally infelicitous.

Indeed, utterances containing sarcastic 'Like' and 'As if' appear to be straightforwardly felicitous only for declarative sentences which are not heard as vehicles for questions, orders, and so on. Thus, while a sentence with the syntactic structure of a question can be used with the effective illocutionary force of asserting some proposition, we can't preface such a sentence with sarcastic 'Like' or 'As if' as a means of denying that proposition:

(15) \#\{Like/As if $\}$ which one of her plans has actually succeeded?

Conversely, although speakers regularly and fluidly employ declarative sentences to ask questions, when such sentences are prefixed with 'Like,' they can no longer be heard as genuine questions. Thus,

(16) Like you are going to do the dishes?

can only be heard as evincing skepticism about the possibility that the addressee might take care of washing up: the embedded sentence cannot be processed as having interrogative force.

These restrictions on 'Like'-prefixed sarcasm with respect to illocutionary force also extend to so-called "illocutionary adverbs." Bare sarcasm easily 'scopes over' or encompasses both illocutionary adverbs like 'surely' or 'frankly', and also what Green (1997) calls “parenthetical attitudinatives,” such as 'as I claim':

(17) They must surely understand that the only thing keeping you from accepting their generous offer is your anxiety that teaching five courses per semester will leave you with no time to cultivate the elegant lifestyle that adjunct faculty are expected to maintain.

(18) Frankly, I believe we should hire her at once.

(19) Silicon Valley is, as I have often claimed, simply a delightful place to live.

In these cases, far from the illocutionary adverb's expression of sincerity conflicting with the overall utterance's sarcasm, the speaker's pretence at sincerity adds more fuel to the sarcastic flame. By contrast, however, none of these sentences can be felicitously prefaced with sarcastic 'Like' or 'As if'.

\subsection{Narrow Focus and Presupposition}

We might sum up the first difference by saying that bare sarcasm has a broader application than 'Like'-prefixed sarcasm, insofar as it can encompass a wider range of illocutionary forces and indications of illocutionary force. The second difference is that bare sarcasm can also be much more narrowly focused 
than 'Like'-prefixed sarcasm. In a wide range of cases, bare sarcasm can 'scope over' just a single expression or phrase within the sentence uttered, while leaving the rest of the sentence standing as the object of sincere commitment. So, for instance, a speaker might utter

(20) Your fine friend is here.

in order to sincerely communicate that a certain individual is present, while also expressing skepticism about this person's being a fine friend. However, if the same sentence is prefixed with 'Like' or 'As if', then the speaker unavoidably commits herself to the relevant person's not being present. Similarly, a sarcastic utterance of

(21) The man who rescued this city from certain ruin is now planning to run for mayor.

can easily communicate the speaker's sincere commitment to the proposition that a certain individual $X$ is running for mayor, while expressing skepticism about whether $X$ really rescued the city and whether it really was headed for certain ruin. ${ }^{5}$ In any case, in (21), much as in (20), sarcasm about the identifying descriptive material can be combined with sincerity about the predicative content. If we assume, as many linguists do, that this descriptive material is presupposed rather than asserted, then it appears that bare sarcasm can target just an utterance's presuppositions while leaving its focal content as sincerely asserted. ${ }^{6}$

The available interpretations become very different when we prefix the same sentence with 'Like' or 'As if', as in

(22) $\{$ Like/As if $\}$ the man who rescued this city from certain ruin is now planning to run for mayor.

Now the utterance definitely commits the speaker to denying that a salient individual $X$ is planning to run for mayor. Thus, where bare sarcasm can easily target just presuppositional material, 'Like' must target at least some of the uttered sentence's asserted content. Further, it is most natural, though perhaps not obligatory, to hear the speaker of (22) as assuming that $X$ did indeed rescue the city from ruin, so that the sarcasm triggered by 'Like' is restricted to just focal, and not presuppositional, material.

This same pattern of contrasts between bare and 'Like'-prefixed sarcasm is exemplified even more clearly with presuppositions that are triggered by predicative rather than descriptive material. Thus, consider

(23) The man who rescued this city from certain ruin now intends to save Akron from its looming debacle, too. 


\section{6 / Elisabeth Camp and John Hawthorne}

As with (21), a sarcastic speaker of (23) may communicate skepticism about whether the individual $X$ being talked about really does satisfy the identifying description. In addition, she may also communicate skepticism about the presuppositions associated with the predicate. All of this is fully compatible with the speaker's sincerely asserting that $X$ does genuinely intend to undertake something similar in Akron to his actions in the first city. However, if we prefix (23) with 'Like' or 'As if', as in

(24) $\{$ Like/As if $\}$ the man who rescued this city from certain ruin now intends to save Akron from its looming debacle, too.

then the interpretive expectations are reversed. Now, just as in (22), the speaker is at a minimum committed to denying that the relevant individual plans to do the relevant thing to Akron; the sarcastic 'inversion' cannot be restricted to just the presuppositions by means of which the relevant individual and intended actions are identified. Further, it is much more natural to hear the speaker as endorsing those presuppositions - that $X$ really did rescue the city, and that his intended actions really would benefit Akron if he were to undertake them - than with bare sarcasm.

\subsection{NPI Licensing}

The third difference between bare and 'Like'-prefixed sarcasm that we want to note is the most systematic, dramatic, and unexpected. Sarcastic 'Like' and 'As if' clearly license Negative Polarity Items (NPIs), while bare sarcasm does not. NPIs are expressions, like 'ever', 'any', 'yet', 'lift a finger' or 'budge an inch', which are syntactically restricted to environments with certain semantic properties. For instance, NPIs occur happily in simple sentences containing the determiner 'No', but cannot occur when 'No' is replaced by 'Some'. Thus,

(25) No dog has ever bothered me. / No dog has any courage.

are good, but

(26) \# Some dog has ever bothered me. / Some dog has any courage.

are bad. The range of NPI licensers is quite diverse, and it is a controversial matter just what distinctive properties they all share. For determiners at least, the relevant trait seems to be downward entailingness (Ladusaw 1979). But this cannot be the whole story: antecedents of conditionals, questions, and expressions of surprise all license NPIs, but the criterion of downward entailingness can't be straightforwardly extended to those cases. For the moment, we are merely 
interested in the fact that 'Like' and 'As if', but not bare sarcasm, license NPIs at all. Thus, for instance,

(27) It's not true that I was going to give him any money.

(28) I wasn't going to give him any money.

(29) $\{$ Like/As if $\}$ I was going to give him any money.

are all perfectly fine, but

(30) \# I was going to give him any money.

is terrible, no matter how scornful and drippingly sarcastic the tone in which it is uttered may be. In (29), 'Like' licenses an NPI in predicative position; but like sentential negation, 'Like' also licenses NPIs in subject position, as in

(31) $\{$ Like/As if/It's not true that $\}$ anyone cares about her silly problems.

This is just as we should expect, given that unlike quantifiers, both sentential negation and 'Like' take whole sentences as inputs. Examples like (29) and (31) are by no means exceptional:

(32) $\{$ Like/As if $\}$ they're ever going to be able to find the real killer.

(33) $\{$ Like/As if $\}$ she's all that smart herself.

(34) $\{$ Like/As if $\}$ he'll budge on that issue.

(35) $\{$ Like/As if $\}$ he had given any thought to the question before they asked him.

(36) $\{$ Like/As if $\}$ those guys believe a word they say.

(37) $\{$ Like/As if $\}$ she bothered to check whether his papers were complete.

(38) $\{$ Like/As if $\}$ I've talked to her in weeks.

(39) $\{$ Like/As if $\}$ that relationship is going to last long.

(40) $\{$ Like/As if $\}$ I would be seen dead in a ditch with him. ${ }^{7}$

(41) $\{$ Like/As if $\}$ he has ever lifted a finger to help anyone besides himself.

(42) $\{$ Like/As if $\}$ he gives a rat's ass.

(43) $\{$ Like/As if $\}$ I give a damn if I ever hear a single word from you again.

Again, note that this behavior is specific to the sarcastic use of 'Like'. Thus, (32) through (43) all become infelicitous if they are heard with 'Like' functioning as a 'Californian' pre-sentential interjection, on a par with

(44) Like, she has some nerve! Coming in here like that!

Likewise, when 'Like' is used as a hedging discourse marker, as in

(45) I have always accorded her, like, the utmost respect. 
then it does not license NPIs. By contrast, as we've seen, 'As if' always licenses NPIs in all the contexts that sarcastic 'Like' does.

We've now identified three fairly dramatic contrasts between bare sarcasm and sarcasm prefixed by 'Like' or 'As if'. First, sarcastic 'Like' can only operate on assertive utterances of declarative sentences without illocutionary markers, while bare sarcasm can encompass speech acts of any illocutionary force, and combines comfortably with markers of illocutionary force. Second, sarcastic 'Like' must 'invert' or deny at least the focal propositional content, while bare sarcasm can be quite narrowly focused, inverting just a single word or phrase within an utterance's focal content, or just its presuppositions, while sincerely presenting the rest of the sentence's semantic content. Third, sarcastic 'Like' invariably licenses NPIs, while bare sarcasm never does.

At a minimum, these contrasts establish that prefixing an utterance with sarcastic 'Like' is not just a stylistic variant on bare sarcasm, akin to a heavily dripping tone. In marked contrast to the flexibility demonstrated by bare sarcasm, 'Like'-prefixed sarcasm exhibits sharp, robust and systematic semantic and syntactic constraints. It is standard linguistic methodology to assume that such systematic behavior requires some sort of linguistic explanation. Specifically, semanticists often point to NPI licensing as evidence for the very existence of a distinctively semantical effect, on the ground that a predictive syntactic theory of NPI-licensing must be sensitive to the semantic behavior of those licensors, such as the fact that determiners are downward entailing. There are important questions about this standard methodology - in particular, about precisely when we should posit semantic, as opposed to merely pragmatic, explanations for linguistic phenomena (for discussion in the context of bare sarcasm, see Camp (ms.)). Specifically, there is evidence that pragmatic factors can affect NPI licensing in particular (Linebarger 1987, Krifka 1995, Israel 1996, von Fintel 1999, Chierchia 2004) - though there is also a pervasive suspicion that these factors must always have a semantic trigger. At this point, however, we need to investigate the prospects for a coherent syntactic and semantic theory of sarcastic 'Like' and 'As if'. Only once we know whether such a theory is possible, and what its theoretical costs might be, will we be in a position evaluate whether we should abandon the standard methodological assumptions, either in this case or more generally.

\section{§2: A Distinctive Syntactic Feature for Sarcastic 'Like'}

In this section, we focus on a particular feature of sarcastic 'Like' and 'As if', one that is intimately connected to the second phenomenon we identified in $\S 1$. This is the simple syntactic fact that sarcastic 'Like' and 'As if' always occur at the beginning of an entire sentence, and their scope is always the entire following sentence. This applies even when the overall sentence itself contains sentential clauses as constituents: even then, 'Like'/'As if' must occur at the front of the 
entire sentence, rather than at the front of a constituent sentential clause, and its scope must be the entire sentence. For instance, if a sentence containing a conjunction begins with sarcastic 'Like', the scope of the sarcastic 'inversion' or denial must extend over the entire conjunction. Thus, one cannot hear

(46) Like John will come to the party and Janet will \{too / not $\}$.

as sarcastically denying the first conjunct but sincerely affirming the second. Here again, we find a marked contrast with bare sarcasm. For example, it is fairly easy to generate utterances of conjunctive sentences in which only the second conjunct is heard sarcastically, as in

(47) I'm sitting here at home sick as a dog and I am sure you are really worried about me.

But one cannot insert sarcastic 'Like' or 'As if' in front of the second conjunct in (47): 'As if' is straightforwardly infelicitous, and 'Like' is felicitous, if at all, only if it is heard as an interjection or quasi-quotational device.

The fact that sarcastic 'Like' and 'As if' are strongly front-preferring and must scope over the entire sentence nicely explains several of their notable features. First, it explains the fact, noted in $\$ 1.2$, that they must 'invert' the entire propositional content of the sentences they scope over, and not just a single word or phrase. Second, it also explains the fact that on their most natural reading, utterances of sentences containing 'Like' and 'As if' commit the speaker to the sentence's presuppositions, but also that a reading on which the speaker does not accept those presuppositions is available. The naturalness of the first reading is explained if we assume that 'Like' functions syntactically like a standard sentential operator, so that the presuppositions of the embedded sentence 'project' as presuppositions to the larger sentence. On the other hand, this assumption also predicts the availability of the second reading: in general, speakers can get away with violating a sentence's presuppositions, but only if the presupposition is mutually assumed to be both salient and false, as in Donnellan's (1966, 291) example (slightly altered here) of an utterance of

(48) The King of France is in his counting house.

for which the speaker and addressee both believe that the person being talked about is a pretender to the throne.

The fact that sarcastic 'Like' and 'As if' are syntactically front-preferring also explains another distinctive fact, that they cannot occur in the consequents of conditionals, as in

(49) \# If he is coming then $\{$ like/ as if $\}$ I am really happy. 
This stands in marked contrast to other sorts of sentences, including orders and questions, which can happily occur in the consequent, as in

(50) If he is coming then shut the door.

(51) If he is coming then why are you standing around?

What is the explanation for this contrast? It cannot derive from a general principle to the effect that we are capable of understanding conditional orders and questions but not conditional sarcasm, because bare sarcasm can perfectly well occur in the consequent of a conditional, as in

(52) If she comes then I'll be really happy.

Rather, we claim that it is only the syntactically front-preferring nature of sarcastic 'Like' that blocks it from occurring in the consequent. To see why, consider modalized conversations, in which a counterfactual condition and its consequence are broken into distinct sentences, as in

(53) A: He might come.

B: $\{$ Like/ As if $\}$ that would help anyone.

(54) A: He might have a lot of money.

B: $\{$ Like/ As if $\}$ he would give it to me if he did.

In such a context, sarcastic 'Like' is perfectly capable of attaching to some putative consequence of a merely conditional assumption. Thus, there is no general prohibition either on sarcasm in the consequent of a single conditional sentence, or on sarcastic 'Like' or 'As if' being modally subordinated. The fact that one cannot express this modal relation by inserting 'Like'-prefixed sarcasm claim into the consequent of a single sentence thus appears to be due entirely to the syntactic constraints associated with 'Like'.

Our claim that 'Like' is syntactically front-preferring need to be reconciled with the fact that two separate sarcastic 'Like' claims can apparently be conjoined, as in:

(55) Like he will ever help you or like she will ever care what you do.

In this case, the entire construction isn't ill-formed or infelicitous, despite the fact that 'Like' occurs in the middle of the sentence, in apparent contradiction to our hypothesis. On closer inspection, though, we find that we can only explain the available interpretation of a sentence like (55) by assuming that 'Like' is indeed front-preferring. For (55) is heard as expressing a conjunction of two 'inversions', even though it is superficially a disjunction. If we take seriously the fact that sarcastic 'Like' always scopes over the entire sentence, and not merely over the 
specific sentential clause to which it is prefixed, then it is no longer surprising that the sentence is heard as a conjunction. Given that sarcastic 'inversion' is something close to negation or denial, it seems highly plausible that De Morgan's Law should hold for sarcastic inversion - in which case 'inverting' a disjunction ( $\mathrm{P}$ or $\mathrm{Q}$ ) should be tantamount to inverting each of $\mathrm{P}$ and $\mathrm{Q}$. The only puzzle that remains is why the second occurrence of 'Like' is syntactically permissible in this case, given that 'Like' is generally front-preferring. A natural idea to explore is that when 'Like' occurs at the beginning of a sentence, it is sometimes permissible, though not obligatory, to echo it later in the sentence. The second occurrence is then strictly speaking redundant - a merely pragmatically useful reminder of the entire sentence's sarcastic force. This suggestion is supported by the observation that sarcastic 'Like' or 'As if' can only occur mid-sentence when the entire sentence is prefixed by 'Like' or 'As if'. ${ }^{8}$

\section{§3: What Is the Semantic Contribution of 'Like'?}

In $\S 2$, we saw that a surprisingly simple syntactic fact could explain several notable features of sarcastic 'Like' and 'As if'. Given the features we have identified to this point, what can we say about the possible semantic contribution of these expressions? Because sarcasm in general, whether bare or 'Like'-prefixed, has the effect of inverting or otherwise undermining a sincere utterance of the relevant sentence, it seems clear that semantically, we should treat sarcastic 'Like' as somehow analogous to negation. Further, given its syntactic behavior, we know that sarcastic 'Like' must be something close to a sentential operator: it must take as its input at least the propositional content expressed by the entire sentence. In this section, we develop two alternative theories, each of which is compatible with these two basic assumptions and with the evidence we have assembled to this point, and we suggest some considerations that may adjudicate between them. Both theories contend that the contribution of 'Like' is semantic and not merely pragmatic.

The first theory treats 'Like' and 'As if' as having the semantic content of sentential negation: they take as input the proposition expressed by the entire following sentence, and deliver as output the negation of that sentence. A natural way to motivate this view is to suggest that the surface expressions 'Like' and 'As if' are really elliptical for 'It is not like' and 'It's not as if'; this assumption smoothly delivers both of our basic syntactic and semantic assumptions. However, in order to explain the fact that unlike 'It's not like', sarcastic 'Like' and 'As if' cannot be used to negate sentential clauses within more complex sentences, the theory must also add a separate, purely syntactic requirement that the expressions are front-preferring.

The second theory, inspired in part by some work of Mitchell Green, treats sarcastic 'Like' and 'As if' as expressing an illocutionary force rather than a truth-functional operator. ${ }^{9}$ The natural way to implement this claim is to assign 
'Like' a function from propositions to illocutionary act types, where the force of the act is denial, or something roughly equivalent. Thus, according to the second view, the semantic content of

(58) Like George will come to the party.

is not a proposition at all, but rather the illocutionary act type of denying that George will come to the party.

One way to motivate assigning 'Like' an illocutionary force equivalent to denial is to pump the intuition that in general, when speakers utter declarative sentences sarcastically, the conversational effect is not one of actually asserting the negation of the proposition semantically expressed, but rather one of mocking or expressing skepticism about that proposition. As we saw, not all sarcasm is directed at the propositional content semantically expressed by the core sentence: for bare sarcasm with illocutionary forces other than assertion, as in (6) through (10), the object of sarcasm is often the entire speech act that would have been undertaken by a sincere utterance, including the force and content of its implicatures. By contrast, 'Like'-prefixed sarcasm does seems always to be directed at the truth-value of the proposition semantically expressed: for instance, in (58) the speaker's attention is directed toward the proposition that George will come to the party. But one might still hold that an utterance of (58) is similar to the analogous bare sarcastic utterance of the embedded sentence in the sense that both mock, denigrate, or deny the possibility that the embedded sentence could be true, rather than actually committing the speaker to the truth of its negation.

Philosophers have typically been reluctant to assign illocutionary act types as semantic values for linguistic expressions - to treat, say, 'disgusting' as expressing the act of disapproving, or 'if-then' as expressing the act of making a hypothetical statement. Indeed, Geach $(1965,455)$ attributes to Frege the view that analyzing denial as something other than simple assertion of the negation is not merely "a futile complication," but that it "cometh of evil." The general objection to assigning illocutionary forces as semantic values is that there are familiar uses of the expressions to which one might be tempted to assign illocutionary acts as semantic values where the user does not actually undertake the relevant act. Bare sarcastic utterances of orders, promises, and questions are one obvious (and obviously relevant) example. Further, as Frege (1918) and Davidson (1979) point out, an actor on a stage uses words and sentences with their normal meanings, but only pretends to commit himself to the concomitant acts of assertion, promising, and the like. Likewise, a speaker who utters the relevant expression or construction in the midst of conditional reasoning, as with the occurrence of an order in

(59) If the Soviets launch a nuclear missile, hit the red button to initiate a debilitating counterattack.

merely conditionally commits herself to the relevant speech act. 
If the second view is to be at all plausible, then, it cannot amount to the claim that whenever one utters a sentence of the form 'Like P', one thereby denies P. We must distinguish sharply between semantically expressing a proposition/force combination and actually performing the illocutionary act of presenting that proposition with that force. ${ }^{10,11}$ Given this distinction, the second view claims that 'Like P' semantically expresses the illocutionary act of denying P; only insofar as one actually commits oneself to that speech act content does one undertake a denial of $\mathrm{P}$. Thus, in particular, when a speaker utters 'Like P' within a modally subordinated context of the sort exemplified in (53) and (54), her denial of $\mathrm{P}$ is merely conditional. It is outright commitment to a force/proposition complex that generates the speech act appropriate to the force.

Let us look at how the two theories might explain some of the data we have considered. First, consider the fact that sarcastic 'Like' and 'As if' can only apply to declarative sentences that are not being used as vehicles of some force other than assertion. The most promising tack for Theory 1 is to explain this phenomenon syntactically. It can adopt the assumption, common among linguists, that assertion is syntactically unmarked, while other illocutionary forces typically are marked. Then, Theory 1 can explain the phenomenon, so long as it is willing to postulate a special syntactic rule for 'Like', to the effect that it selects exclusively for sentences that lack a force marker. (On the assumption that the interrogative use of a declarative involves the insertion of a force marker, whose presence is indicated by intonational contour, this syntactic story can also explain why 'Like' cannot felicitously combine with such uses.) What will Theory 2 say about the relevant combinatorial facts? It might simply adopt the syntactic explanation given by Theory 1 . But Theory 2 can also offer a semantic explanation of the phenomenon. Assuming that the illocutionary force of assertion never appears as a semantic constituent, it can hold that declarative sentences have as their semantic content a bare proposition, rather than a force/proposition complex. The view also posits a general speech-acttype, of commitment. ${ }^{12}$ Commitment to a bare proposition yields assertion, while commitment to a force/proposition complex yields a speech act appropriate to that force. (Again, as we noted above, just as one can express a proposition without committing oneself to it, so one can also express a force/proposition complex without committing oneself to it.) Given these background assumptions, the following explanation emerges for the fact that sarcastic 'Like' can only combine with declarative sentences: 'Like' combines with a bare proposition to produce a force/proposition complex. Insofar as the embedded sentence itself already expresses such a complex, this produces a semantic type mismatch. As a result, since only declarative sentences semantically express bare propositions, 'Like' can only combine with declarative sentences. Note that Theory 1 is barred from offering such a semantic story, given that it does not posit illocutionary forces as part of semantic content; according to it, the combinatorial restriction is purely syntactically driven. ${ }^{13}$ 
Second, consider the fact that sarcastic 'Like' and 'As if' license NPIs. According to Theory 1, 'Like' and 'As if' have precisely the same semantic effect as negation, and so they also induce a downward-entailing environment. By contrast, Theory 2 claims that because denial is a negative attitude, it generates the illocutionary analogue of a downward-entailing environment: if one is committed to denying that there are any dogs in the park, or that anyone will come to the party, then one is also thereby committed to denying that there are any yellow dogs in the park, or that George will come to the party (cf. Green 2000 on illocutionary validity). This involves no significant extension of a standard theory of NPI licensing, because the assumption that illocutionary forces, and not just propositional, truth-conditional properties, can affect NPI licensing is already needed to explain the fact that questions license NPIs.

For the reasons discussed in $\S 2$, neither Theory 1 nor Theory 2 can offer an internal, semantic explanation for why sarcastic 'Like' should be barred from the consequents of conditional sentences; only a brute appeal to a front-preferring syntactic constraint will do. Theory 1 relies on this same constraint to explain why 'Like' also cannot occur in the antecedents of conditionals. Once again, a proponent of Theory 2 is free to appeal to this constraint, but she is also in a position to offer a semantic explanation. The fact that non-assertive illocutionary act types, such as orders and questions, are generally barred from this position gives us reason to think that the antecedent takes a bare proposition as input. According to Theory 2, then, the fact that sarcastic 'Like' cannot occur in the antecedent is overdetermined: not only is it prohibited by a purely syntactic constraint, but it is also of the wrong semantic type.

So far, we have not found powerful reasons to prefer one theory over the other: both have natural explanations for the fact that 'Like' combines only with declarative sentences and licenses NPIs, but both need to appeal to an otherwise unrationalized syntactic constraint in order to explain why it cannot occur in the consequents of conditional sentences. At best, Theory 2 has two modest advantages. First, it does a better job of capturing the rather vague and subtle intuition that in using sarcastic 'Like', speakers do something that is more like denying $P$ than like asserting Not $P$ outright. Second, those who strongly prefer semantic to syntactic explanations may think Theory 2 is better placed to explain the combinatorial behavior of 'Like'. But for many readers, this advantage will be offset by the feeling that assigning illocutionary forces as semantic values is problematic, even unholy. How, then, can we adjudicate between the two views? We offer three tentative considerations in support of Theory 2 -ones that we think are quite instructive for thinking about semantics more generally.

First, Theory 2 is better equipped to deal with the fact that 'Like' must encompass the entire sentence which follows, and not just the first complete sentential clause, on the ground that questions also exhibit the same behavior. Thus,

(60) \# Will you do the dishes or I will do them.

is bad, but 
(61) Will you do the dishes or will I do them?

is fine. Of course, the analogy can only be pushed so far. After all, orders can be combined with assertions, as in

(62) Wash the dishes or I will ground you for a week.

So there is no general ban on embedded sentential clauses having distinct forces from the larger sentence. Still, the similarity between the scopal behavior of 'Like' and of questions shows that 'Like' is not unique, and at least hints in the direction of an explanation. By contrast, Theory 1 has no explanation at all for the behavior exhibited in (60): neither the semantic content it attributes to 'Like' nor the brute front-preferring syntactic requirement by themselves rule out the possibility of 'Like' scoping over just the initial sentential clause in a multi-clause sentence.

Similarly, Theory 2 can point to the fact that like 'Like', other markers of illocutionary force are also incompatible with illocutionary adverbs such as 'luckily' and 'unfortunately'; typically, such force-indicating expressions are restricted to declarative contexts. Thus,

(63) \# Thoroughly revise the paper, frankly, to get a passing grade.

(64) \# Is she, luckily, planning to resign?

(65) \# Can you unfortunately take out the trash now?

are bad, while closely analogous declarative sentences are acceptable:

(66) You must thoroughly revise the paper, frankly, to get a passing grade.

(67) She is, luckily, planning to resign.

(68) Unfortunately, you need to take out the trash now.

Again, the analogy is only partial. 'Yes-no' questions can often take parenthetical attitudinatives, as in

(69) Did she come to the party, as I predicted? ${ }^{14}$

Further, there are some illocutionary-force-indicating devices designed specifically for orders, as in

(70) Drop the gun, like I'm telling you to, and there'll be no more trouble.

At the very least, though, Theory 2 can appeal to the fact that some other illocutionary forces do induce parallel syntactic effects in some contexts, while Theory 1 lacks any explanation for these behaviors.

Our third consideration appeals directly to intuitions about truth and falsity. If Theory 1 is correct, then the semantic content of a claim containing sarcastic 
'Like' should be an appropriate object for evaluation with respect to truth and falsity; while if Theory 2 is correct, then this should not be so. Given this, Theory 2 is supported by the fact that it sounds quite odd to say 'That's true' or 'That's false' in response to utterances of sentences containing 'Like' or 'As if', such as

(32) Like they're ever going to be able to find the real killer.

(58) Like George will come to the party.

Similarly, when a sentence containing 'Like' is uttered as a response to another utterance, then transitional interjections involving 'Yes/No', or 'That's true/false', are typically not felicitous. Thus, in the following dialogue,

(71) A: Her plan will succeed.

B: No. Like her plan is ever going to work.

B's response is not straightforwardly acceptable. Further, if we replace sarcastic 'Like' with 'lt's not true that' or even 'It's not like', which according to Theory 1 are (at least) semantically equivalent to sarcastic 'Like', then the relevant utterances do become felicitous:

(72) A: It's not like he will come to the party.

B: $\{$ No./ That's false. $\}$ He will come.

(73) A: Her plan will work.

B: No. $\{$ It's not true that/ It's not like $\}$ her plan is ever going to succeed.

This behavior is surely surprising on Theory 1 . By contrast, Theory 2 has a natural explanation of the relevant infelicities. It maintains that speech acts in general are not evaluable for truth and falsity qua speech acts; only their propositional contents are so evaluable. Thus, phrases like 'That's true /false' and 'Yes' / No' target semantic contents that are propositions rather than speech acts. As a result, such phrases are not appropriate as responses to utterances that have an illocutionary act type as their semantic content, as Theory 2 claims utterances of sarcastic 'Like' to have. Nor are they appropriate as vehicles of disagreement that target specifically propositional content, as assertions that follow directly upon 'Yes' and 'No' typically are. Again, we don't want to place too much weight on this argument. The data with respect to responses involving 'Yes' are especially difficult to analyze, because 'Yes' can often be followed by an echoic utterance which commits the respondent to the same force/content complex as the original speaker's utterance did, albeit in slightly different terms. We also note that 'I agree' and 'I disagree' are far more acceptable than 'That's true' and 'That's false' in response to 'Like' claims. However, there is some reason to think that 'I agree' and 'I disagree' are more flexible than 'That's true/false', especially in being more easily directed at contents that are communicated but not semantically asserted. But the data are admittedly delicate. 
The fourth and final consideration in support of Theory 2 is that Theory 1 , but not Theory 2, predicts that the semantic contents of sentences containing 'Like' and 'As if', such as

(74) $\{$ Like/ As if $\}$ it will rain.

(75) $\{$ Like/ As if $\}$ George will come to the party.

are themselves perfectly proper objects of belief. We cannot test this prediction in the most straightforward way, by looking at ordinary belief attributions, because both theories agree that the front-preferring syntactic profile of 'Like' prevents it from being embedded in belief constructions, as in

(76) \# Alex thinks that $\{$ like/ as if $\}$ it will rain.

(77) \# Alex believes $\{$ like/ as if $\}$ George will come to the party.

According to Theory 1, syntax alone deprives 'Like' of its full recursive semantic potential, and the badness of (76) and (77) is due entirely to the brute syntactic constraint that 'Like' must occur at the beginning of a sentence; while according to Theory 2, the semantic content of (76) and (77) is also not the right sort of thing to be the object of a propositional attitude. So both theories have an explanation for the badness of 'Like' embedded in attitude ascriptions. Recall, though, that in $\$ 2$, when the same syntactic constraint prevented us from testing the feasibility of conditional sarcastic 'Like' claims directly, by placing 'Like' in the consequent of a single conditional sentence, we instead considered separate sentences in modalized conversations. So too here: we can adjudicate between the two theories by separating the belief attribution and the attributed content into distinct sentences, using the construction made famous by Davidson (1968):

(78) P. She believes that.

As applied to 'Like' and 'As if', this schema produces constructions like the following:

(79) Like Alan has any money. She believes that.

(80) As if anyone will help. She believes that.

Both of the sequences in (79) and (80) are clearly infelicitous. But because 'Like' and 'As if' appear here in sentence-initial position, Theory 1 cannot explain the infelicity by appeal to brute front-preferring syntax. ${ }^{15}$ By contrast, Theory 2 once again has a nice explanation of the infelicity: because illocutionary act types are precisely speech acts rather than propositions, they are not appropriate objects of belief or any other propositional attitudes.

All told, then, we conclude that Theory 2 does a better job of explaining the complex pattern of behavior that we observe with 'Like' and 'As if', offering 
a promising division of labor between syntax and semantics for explaining the distribution patterns for those expressions. If 'Like' does indeed make a semantic contribution, that contribution will almost certainly be of the sort posited by Theory 2. Inter alia, that theory provides semantic explanations for the negative polarity effect of sarcastic 'Like', for why sentences containing sarcastic 'Like' cannot occur in the antecedents of conditionals, why they cannot figure as the objects of belief, and why 'Like' cannot felicitously combine with illocutionaryforce-indicating devices.

No doubt many readers will still be uncomfortable with a proposal that allows illocutionary force to enter into semantic content at all. We urge those readers to ponder carefully their favorite criteria for distinguishing the semantic from the extra-semantic. Once we distinguish between semantically expressing an illocutionary act type and actually undertaking an illocutionary act, the traditional objection to assigning illocutionary forces as the semantic values of linguistic expressions disappears. Those who wish to institute such a prohibition need to come up with better, more nuanced arguments that those typically on offer. Absent such arguments, Theory 2 offers an appealing model for integrating illocutionary force into semantics in an explanatorily fruitful way. $^{16}$

No doubt some readers will also still be uncomfortable with any proposal that grants semantic status to sarcastic 'Like', on the grounds that sarcasm in general is a paradigmatically pragmatic phenomenon. We urge those readers to ponder even more carefully their criteria for identifying what is and is not semantic. As we noted in $\S 1$, sarcastic 'Like' exhibits just the sorts of robust, systematic patterns of linguistic behavior that a semantic theory should be designed to explain - in marked contrast to bare sarcasm, whose behavior is much more variable. Insisting on a purely pragmatic treatment of sarcastic 'Like' risks a semantic/pragmatics distinction that is grounded in dogma rather than in sound tenets of good theory construction.

\section{Notes}

1. The drama need not even be lexical. For example, this 'like' can be followed by grunts, moans or bodily gestures. We say 'public or private' because what follows may reenact thoughts as well as actions. (Thanks to David Manley here.)

2. (6) and (7) are from Kumon-Nakamura et al (1995).

3. Cf. Clark and Gerrig (1984), Wilson and Sperber (1992), Kumon-Nakamura et al (1995).

4. See Camp (ms.) for further discussion of the varieties of sarcastic utterances.

5. Even if the speaker is blatantly skeptical about these features, a hearer will have no trouble identifying who the speaker is talking about, so long as it is mutually known that a certain individual saliently failed to rescue the city from certain ruin, or that some people believe falsely that a certain individual did rescue the city, or some other analogous proposition. 
6. Indeed, bare sarcasm can target just the implicatures associated with an utterance, while leaving the core utterance as fully sincere; see Camp (ms.) for discussion.

7. The NPIs 'last long', 'born yesterday', and 'dead in a ditch' are all strong NPIs, which require licensing by strong licensors. Strong licensors are not merely downward monotonic, as all NPI licensors appear to be, but also anti-additive (e.g. Zwarts 1998, von Fintel 1999), where anti-additivity holds just in case, if a function applies to two arguments, it also applies to their union. We see that 'Like' is downward monotonic from the acceptability of inferences like the following:

(i) Like Sam ate any vegetables. $\rightarrow$ Like Sam ate any peas.

(ii) Like Sam ever lifted a finger to help anyone. $\rightarrow$ Like Sam ever lifted a finger to help you.

(iii) Like anyone ate any vegetables. $\rightarrow$ Like Sam ate any vegetables.

And we see that it is anti-additive from the acceptability of inferences like these:

(iv) Like John ever drinks. Like John ever smokes. $\rightarrow$ Like John ever drinks or smokes.

8. Supposing the account in the text is along roughly the right lines, it would obviously require a fuller specification and explanation of just when 'Like' can be echoed later in the sentence, and what the perceived content of the entire utterance is. In addition, it would be good to examine other cases in which a disjunction sounds conjunctive, and evaluate whether the phenomenon always has a common source.

9. Green (2000) focuses exclusively on parenthetical attitudinatives, such as 'as I claim', and the details of his analysis are different in certain respects, but his general approach to what he calls "illocutionary force indicating devices" can be naturally extended to the present case.

10. Green's distinction between weak and strong illocutionary force indicating devices (IFIDs) marks just this difference: any utterance of a strong IFID outside of quotation marks commits the speaker to the relevant content with the relevant force, while the utterance of a weak IFID only commits the speaker to the relevant force/content combination if the speaker is suitably committed to the larger sentence in which the IFID is embedded. In his (1997), Green argues for the possibility of weak, but not strong, IFIDs; in his (2000) he defends their actuality. In effect, Theory 2 holds that 'Like' is a weak IFID.

11. Not only can one utter a sentence which semantically expresses a certain force without actually performing a speech act with that force, as in the cases discussed by Frege and Davidson; one can also arguably undertake a speech act of a certain force without uttering a sentence which has that force as its semantic content. In particular, as we note in fn. 11, it seems likely that bare sarcasm, as applied to assertion, denies a claim without expressing a sentence that semantically expresses denial.

12. Note that while Theory 2 claims that sentences containing sarcastic 'Like' semantically express a force/proposition complex, it is by no means committed to the claim that bare sarcasm also expresses such a complex. We have seen that Theory 2 is not committed to the view that speech acts always semantically express a force - as we noted, the natural view is that assertion does no such 
thing. It is thus open to Theory 2 to hold that a bare sarcastic utterance of a declarative sentence effectively denies a claim (or some presupposition of a claim) but does not semantically express anything more than a proposition.

13. Can there be sarcastic utterances of 'Like P', which would 'double reverse' the semantic content of 'Like P', to produce something like a sincere utterance of P? Neither theory needs to take a stand on this matter, but in general it's quite difficult to imagine such utterances. The most likely explanation of this is that a sarcastic utterance of 'Like P' is pragmatically unperformable, because the conversational signals one would normally use to indicate one's (bare) sarcastic intent - contextual inappropriateness, dripping tone - have already been deployed in conjunction with 'Like'. Note, however, that in some circumstances an utterance of 'Like P' might be ironic: for instance if B utters (58) at the party, to which it turns out that George has indeed come, in order to echo a previous utterance of (58) by A (cf. Wilson and Sperber 1992) on echoic irony). In such a case, B neither denies nor asserts that George will come, but rather mocks A's earlier denial of the possibility that he would come.

14. This seems to point toward a more general disanalogy between illocutionary adverbs and parenthetical attitudinatives.

15. This test gives similar results for the Californian adolescent retro-'Not' and 'As if', which occur at the end of sentences.

16. Our partiality to a force-theoretic semantic treatment of 'Like' does not, of course, mean that we would endorse analogous force-theoretic treatments for expressions like 'disgusting' and 'If....then'.

\section{References}

Camp, Elisabeth (ms.): "Why Isn’t Sarcasm Semantic, Anyway?"

Chierchia, Gennaro (2004): "Scalar Implicatures, Polarity Phenomena, and the Syntax/ Pragmatics Interface," in Structures and Beyond: The Cartography of Syntactic Structures vol. 3, ed. A. Belletti (Oxford: Oxford University Press), 39-103.

Clark, Herbert and Richard Gerrig (1984): "On the Pretense Theory of Irony," Journal of Experimental Psychology: General 113: 121-126.

Davidson, Donald (1979): "Moods and performances," in Meaning and Use, ed. A. Margalit (Dordrecht: Reidel), 9-20. (1968): "On Saying That," Synthese 19: 130-46.

Donnellan, Keith (1966): "Reference and Definite Descriptions," Philosophical Review 75(3): 281-304.

Frege, Gottlob (1918): “Der Gedanke: Eine logische Untersuchung”, in Beiträge zur Philosophie des deutschen Idealismus I: 58-77.

Geach, Peter (1965): “Assertion,” Philosophical Review 74: 449-65.

Green, Mitchell (2000): "Illocutionary Force and Semantic Content," Linguistics and Philosophy 23: 435-473.

(1997): “On the Autonomy of Linguistic Meaning," Mind 106(422): 217-243.

Haiman, John (1998): Talk is Cheap: Sarcasm, Alienation, and the Evolution of Language (Oxford: Oxford University Press).

Israel, Michael (1996): "Polarity Sensitivity as Lexical Semantics," Linguistics and Philosophy 19: 619-666.

Krifka, Manfred (1995): "The Semantics and Pragmatics of Polarity Items," Linguistic Analysis 25: 209-257. 
Kumon-Nakamura, Sachi, Sam Glucksberg, and Mary Brown (1995): "How About Another Piece Of Pie? The Allusional Pretense Theory Of Discourse Irony," Journal of Experimental Psychology: General 124(1): 3-21.

Ladusaw, William (1982): "On the Notion 'Affective' in the Analysis of Negative-Polarity Items," in Journal of Linguistic Research 1(2): 1-16.

Linebarger, Marcia (1987): "Negative Polarity and Grammatical Representation," Linguistics and Philosophy 10: 325-87.

Quintilian (95/1920): Institutio Oratoria, trans. HE Butler. Loeb Classical Library (Cambridge MA: Harvard University Press).

Siegel, Muffy (2002): "Like: The Discourse Particle and Semantics," Journal of Semantics 19: $35-71$.

von Fintel, Kai (1999): "NPI-Licensing, Strawson-Entailment, and Context-Dependency," Journal of Semantics 16: 97-148.

Wilson, Deirdre and Dan Sperber (1992): “On Verbal Irony,” Lingua 87: 53-76.

Zwarts, Frans (1995): "Nonveridical contexts,” Linguistic Analysis 25(3/4): 286-312. 